Supplement of

\title{
A novel regional irrigation water productivity model for complex cropping patterns in arid regions coupling soil water and salinity dynamics, irrigation and drainage, and shallow groundwater movement
}

Jingyuan Xue ${ }^{1}$, Zailin $\mathrm{Huo}^{1 *}$, Ian White ${ }^{2}$, Isaya Kisekka ${ }^{3}$, Zhuping Sheng ${ }^{4}$, Shuai Wang $^{1}$, Chaozi Wang ${ }^{1}$, Guanhua Huang ${ }^{1}, \mathrm{Xu} \mathrm{Xu}^{1}$

${ }^{1}$ College of Water Resource and Civil Engineering, China Agricultural University, Beijing 100083, China. ${ }^{2}$ Fenner School of Environment \& Society, Australian National University, Fenner Building 141 Canberra ACT 0200. ${ }^{3}$ Univerisity of California Davis, Department of Land, Air and Water Resources and Department of Biological and Agricultural Engineering. ${ }^{4}$ Texas A\&M University, Agriculture Research and Extension Center, El Paso, USA

* Correspondence to: Zailin Huo (huozl@cau.edu.cn)

\section{Contents of this file}

Figure S1 to Figure S3

\section{Figure Captions}

Fig.S1. The representation of (a) regional HRUs division and (b) groundwater boundary condition division.

Fig.S2. Spatial distribution and their control zones of main and sub-main (a) canals and (b) drainage ditches.

Fig.S3. Comparison of the simulated and remote sensing cumulative ET during the crop growing 

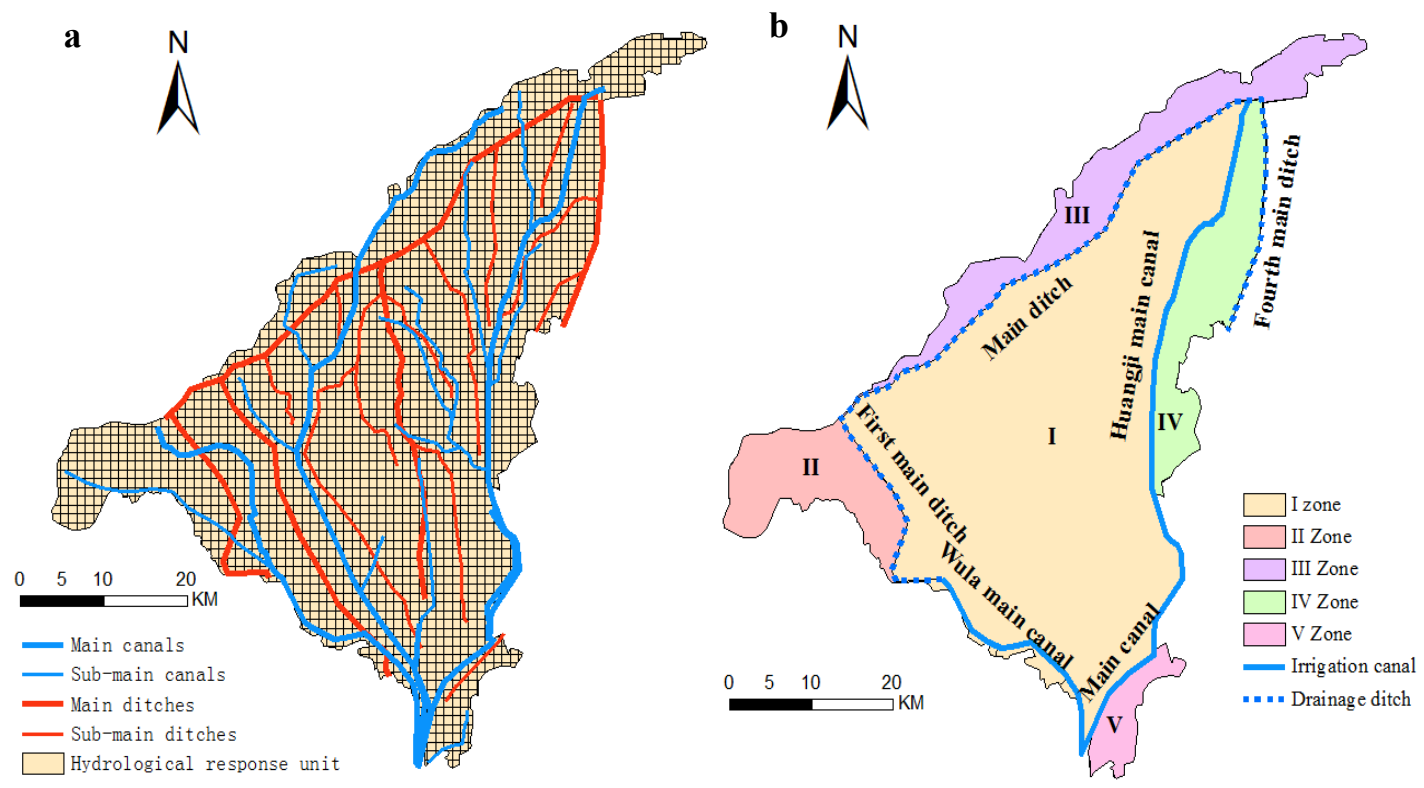

Fig.S1. The representation of (a) regional HRUs division and (b) groundwater boundary condition division.
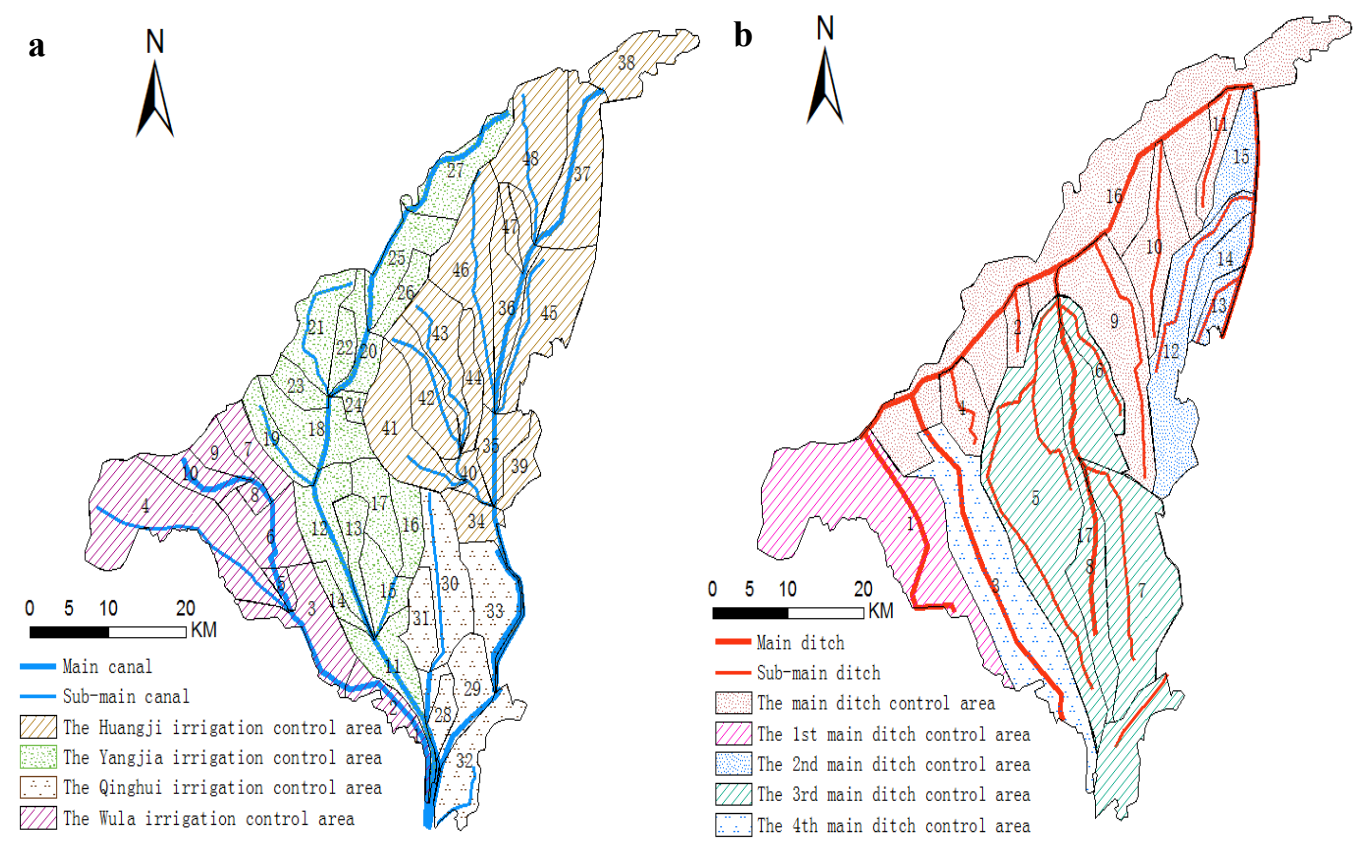

Fig.S2. Spatial distribution and their control zones of main and sub-main (a) canals and (b) drainage ditches. 


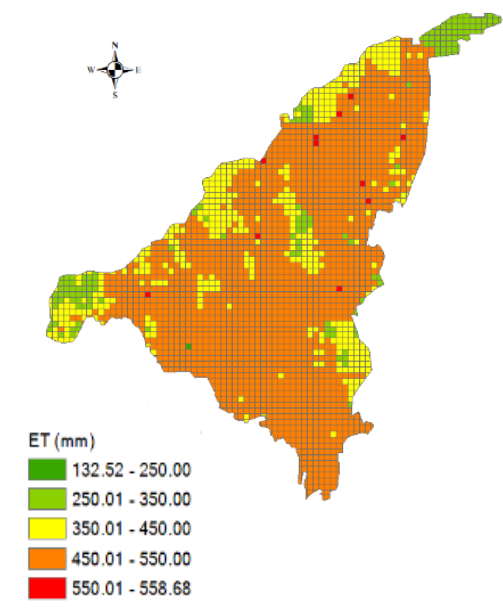

a- Simulated ET (2006)

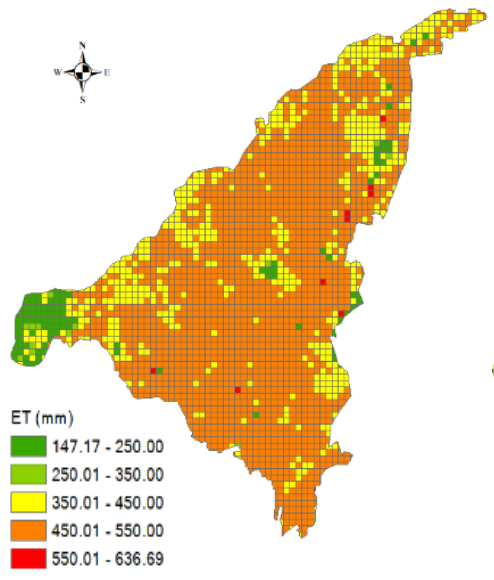

c- Simulated ET (2007)

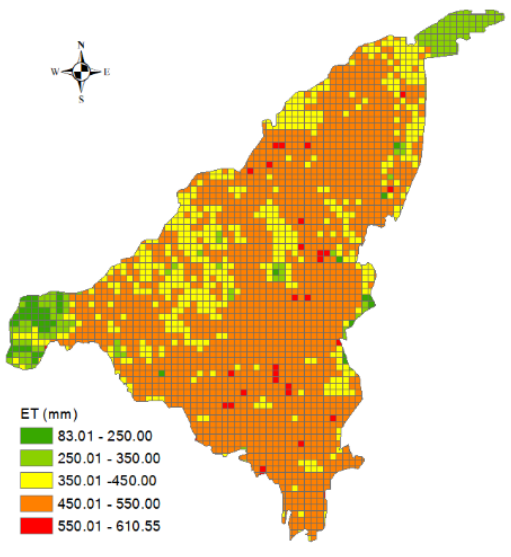

e- Simulated ET (2008)

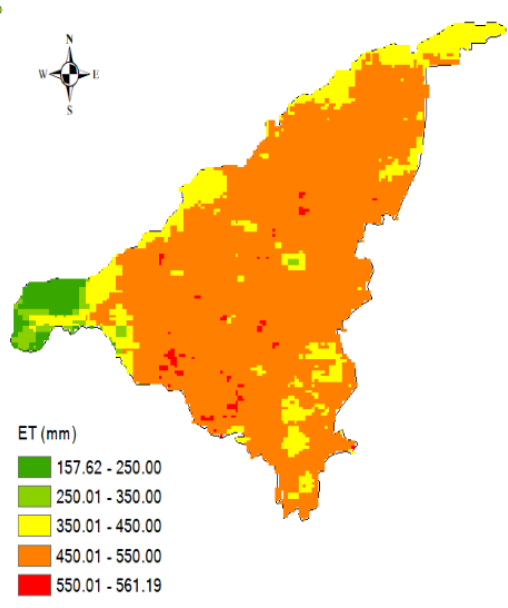

b- Remote sensing ET (2006)

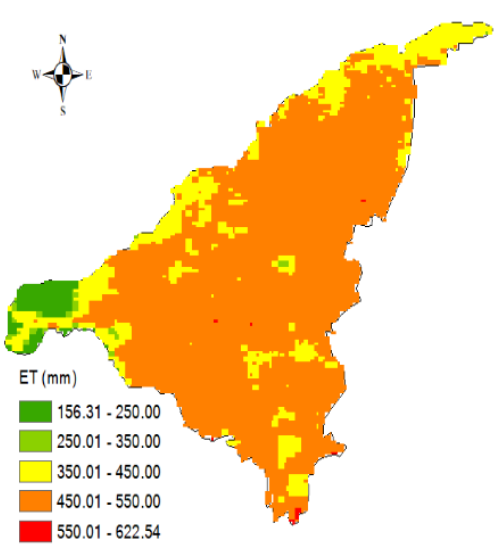

d- Remote sensing ET (2007)

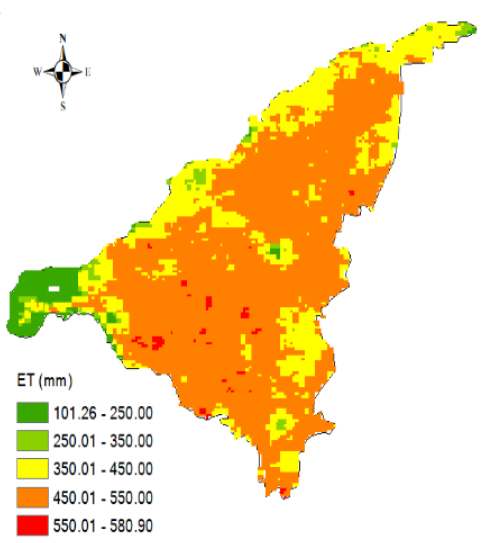

f- Remote sensing ET (2008) 


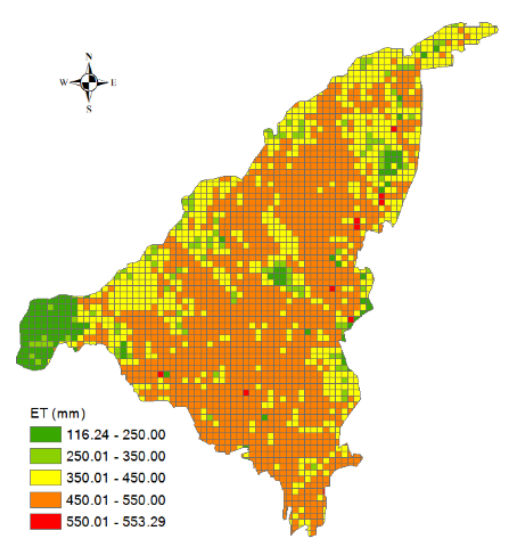

g- Simulated ET (2009)

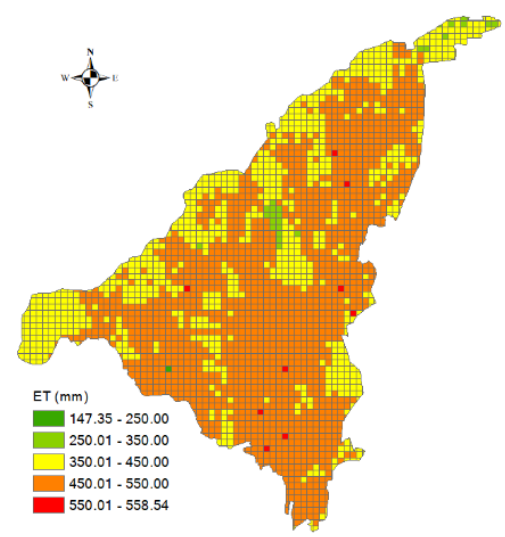

i- Simulated ET (2010)

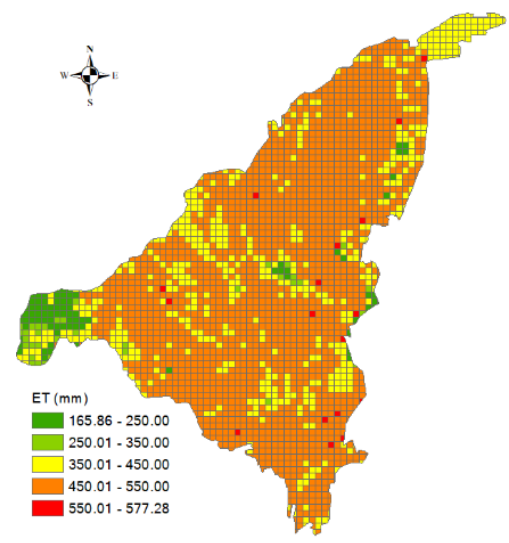

k- Simulated ET (2011)

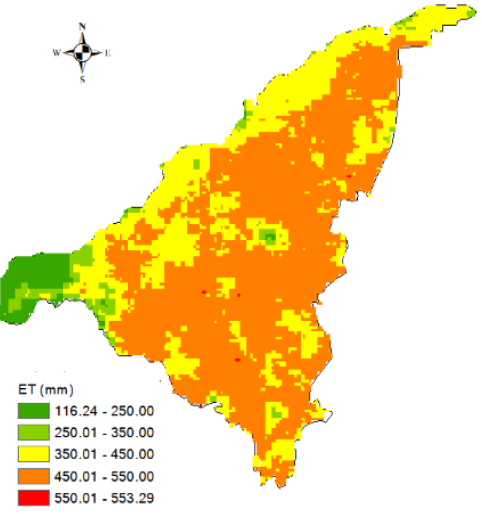

h- Remote sensing ET (2009)

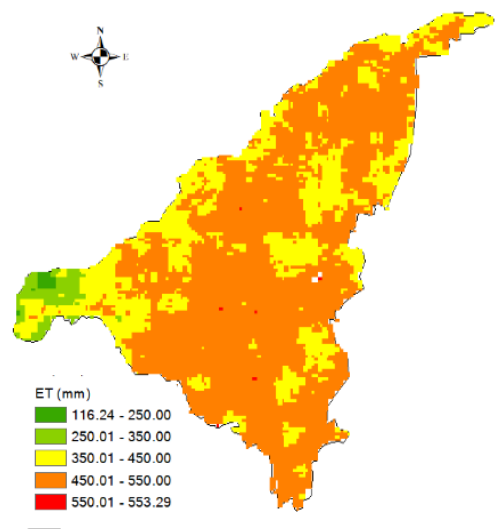

$$
\text { j- Remote sensing ET (2010) }
$$

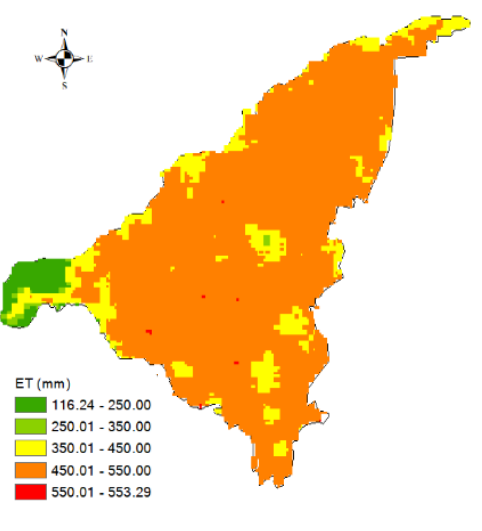

1-Remote sensing ET (2011) 


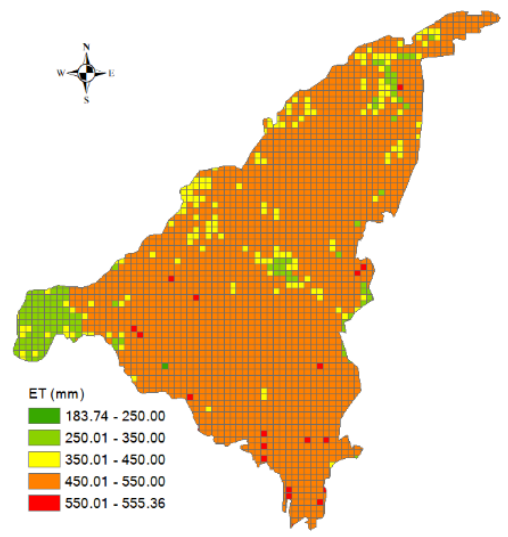

m- Simulated ET (2012)

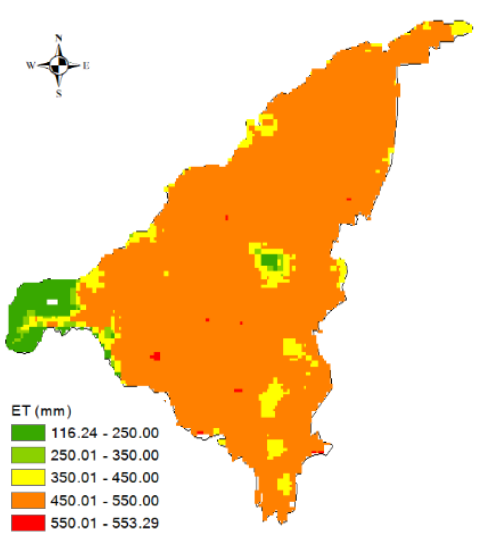

n- Remote sensing ET (2012)

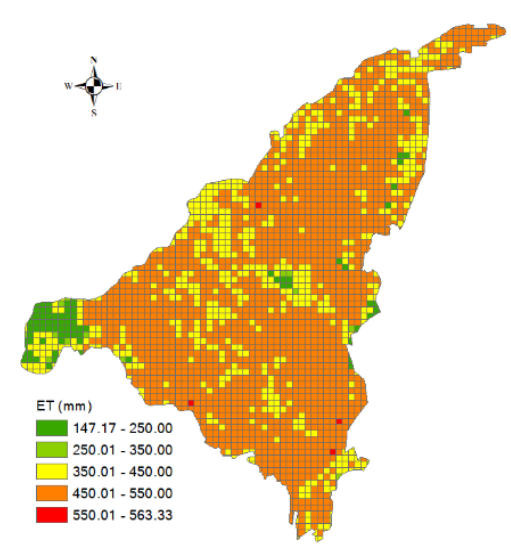

o- Simulated ET (2013)

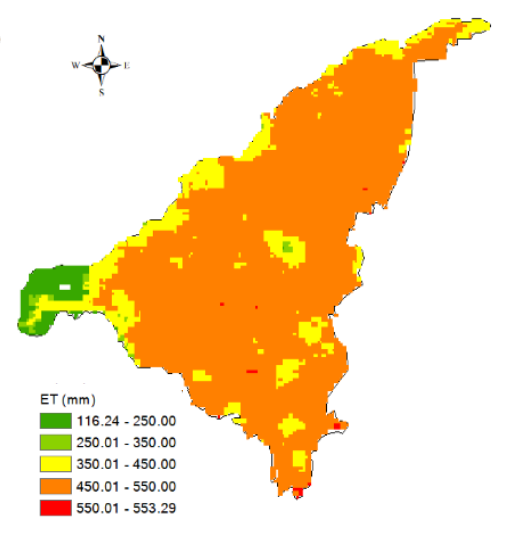

p- Remote sensing ET (2013)

Fig.S3. Comparison of the simulated and remote sensing cumulative ET during the crop growing season in the years of 2006-2013. 